Al-Khwarizmi Engineering Journal,Vol. 12, No. 4, P.P. 102- 110 (2016)

Al-Khwarizmi

Engineering

Journal

\title{
Comparative Study of Performance and Emission Characteristics between Spark Ignition Engine and Homogeneous Charge Compression Ignition Engine (HCCI)
}

\author{
Nahedh Mahmood Ali \\ Department of Materials Engineering / University of Technology \\ Email: nahidh.mahmood60@gmail.com
}

(Received 25 January 2016; accepted 15 June 2016)

http://dx.doi.org/10.22153/kej.2016.06.003

\begin{abstract}
Many researchers consider Homogeneous Charge Compression Ignition (HCCI) engine mode as a promising alternative to combustion in Spark Ignition and Compression Ignition Engines. The HCCI engine runs on lean mixtures of fuel and air, and the combustion is produced from the fuel autoignition instead of ignited by a spark. This combustion mode was investigated in this paper. A variable compression ratio, spark ignition engine type TD110 was used in the experiments. The tested fuel was Iraqi conventional gasoline $(\mathrm{ON}=82)$.

The results showed that HCCI engine can run in very lean equivalence ratios. The brake specific fuel consumption was reduced about $28 \%$ compared with a spark ignition engine. The experimental tests showed that the emissions concentrations were reduced by $91.27 \%$ for $\mathrm{NOx}, 85.99 \%$ for $\mathrm{CO}, 78.91 \%$ for $\mathrm{CO}_{2}$, and $83.56 \%$ for unburned hydrocarbons compared to the SI engine. HCCI engine produced little noise with about $26.68 \%$ less than SI engine.
\end{abstract}

Keywords: Homogeneous Charge Compression Ignition, HCCI, gasoline fuel, auto-ignition and combustion.

\section{Introduction}

The homogeneous charge compression ignition system (HCCI) can be considered as an attractive system with low emitted emissions, but lower efficiency compared to conventional engines. The HCCI engine emits low NOx emissions, and virtually no particulate matters (PM) emissions. However, the marketing of HCCI technology still represents a huge challenge because of the narrow field of operation and the difficulties associated with the combustion phase [1].

The HCCI depends on the attain of a homogeneous mixture of the fuel by mixing the fuel and air before combustion starts and that this mixture is auto-ignited due to the high temperatures of the compression stroke [2]. The HCCI system is similar to SI system as both systems use a premixed charge. In the same time, HCCI system is similar to CI system as both systems are auto-ignited to initiate combustion. However, the HCCI combustion process varies totally from the two types [3].

When the mixture is compressed, its temperature and pressure increase. When the timing is controlled successfully, the mixture auto-ignites at a couple of degrees before TDC. The combustion starts at many locations simultaneously [4]. After ignition, the gas that burned first will expand and thereby compress the part of the gas that did not burn yet. This compression, together with the overall rise in temperature and the time necessary for the chemical kinetics to start, leads to auto-ignition of the rest of the mixture. HCCI combustion has thus no flame propagation [5].

As far as the mixture preparation is concerned, one approach is port-injection, leading to a nearly homogeneous charge as in the SI engine. Another 
one is a direct injection (DI), in which the fuel can be injected very early in the compression stroke or a later stage under very high pressure. The aim of both methods is to obtain an almost homogeneous charge [6].

The HCCI engine has no direct means to control the timing of ignition, unlike the SI and CI engines. The SI engine has ignition timing, and CI diesel cycle engine has a fuel injection beginning, and both are controlling directly the start of combustion [7]. However, in the HCCI engine, the ignition is controlled by controlling the conditions of the charge and the cylinder walls at a time when the intake valve closes. The ignition control is one of the biggest challenges with the practical implementation of HCCI engine technology [8]. The ignition timing cannot be controlled only indirectly through adjustments in the preparation of the cylinder charge [9].

The most common technological means to facilitate the self-ignition are:

1- Increasing the compression ratio [9].

2- Using intake air heating [10].

3- Trapping a high residual gas fraction (RGF) by some method that can alter valve timing and/or lift (e.g. variable valve timing (VVT), electronic valve control (EVC)) [11].

4- Running the engine on mixtures of fuel with different reactivates and control each fuel fraction [12].

At present, several problems are blocking the road to successful integration of the HCCI concept in automotive applications: complex and expensive solutions (e.g. variable valve train systems) may be necessary to make HCCI combustion possible and the operating window of smooth HCCI operation is still of limited size. However, the most serious problem is the difficulty to control the moment of auto-ignition and the energy release rate. As the mixture in the cylinder is premixed, and no spark plug is used, the chemical processes determine the onset of auto-ignition, as well as the fuel burn rate [13].

Çınar et al. studied the effect of variable equivalence ratios and constant intake air temperature of $80{ }^{\circ} \mathrm{C}$ on $\mathrm{HCCI}$ engine operation experimentally. Two strategies were used in the study to obtain exhaust gas trapping and HCCI operation. The study findings showed that incylinder pressure and heat release rate decreased using, and more residual gases were trapped. The indicated thermal efficiency increased at 1000 rpm engine speed and stoichiometric air/fuel ratio [14].

Zhao reported that eliminating the local rich air-fuel mixtures and reduced combustion temperature in HCCI operation mode enable to decrease the PM and NOx emissions trade off without affecting the high thermal efficiency [15]

Uyumaz conducted an experimental study to determine the impact of several blends of $n$ heptane-gasoline on HCCI combustion mode in four stroke port injection Ricardo Hydra test engine. The investigation was carried out at a constant engine speed of $1500 \mathrm{rpm}$ and $K=2$. The tests examined the impact of inlet air temperature on HCCI combustion. The study results clarified that increasing the inlet air temperature forced the start of combustion to advance with all the tested blends. The results revealed that $\mathrm{CO}$ emissions decreased, and $\mathrm{CO} 2$ levels increased with the increase of inlet air temperature, due to better oxidization. The Maximum measured $\mathrm{CO}$ emissions were $0.144 \%$ (vol.) with B40 (40\% nheptane and $60 \%$ gasoline), $0.138 \%$ (vol.) with B30 (30\% n-heptane and 70\% gasoline) at $313 \mathrm{~K}$ inlet air temperature. $\mathrm{HC}$ emissions decreased with increasing the inlet air temperature due to rapid combustion that caused an improvement in chemical reactions at high inlet air temperatures. The maximum measured $\mathrm{HC}$ concentrations were $440 \mathrm{ppm}$ and 438.88 for B30 blend at $313 \mathrm{~K}$, and $333 \mathrm{~K}$ inlet air temperatures respectively. The study indicated that NOx levels were near zero at high combustion temperatures, due to the low temperature of combustion. At high inlet air temperatures, the measured NO concentrations were about 1 to 2 ppm [16].

The goal of this work is to compare practically between two combustion systems, (spark ignition engine and $\mathrm{HCCI}$ engine). The comparison will be for limited engine conditions; which were 1500 rpm engine speed, and full load operation. The engine speed of $1500 \mathrm{rpm}$ was selected as it is relevance to a car's engine runs in city streets. The full load operation was chosen to examine the maximum operation limit before knock limit.

\section{Experimental Set Up}

This study was carried out using a single cylinder, four strokes, and variable compression ratio, spark ignition engine and speed, type TD110, using hydraulic dynamometer, Fig. 1 illustrates the engine rig and the measuring instruments. Table 1 gives this engine specification.

The engine was adjusted to overcome limitations in power output by making it full open throttle and adjusting the spark timing to be the optimum one for every operating condition. The 
engine was also modified to use HCCI combustion mode by conversion conventional diesel combustion at high loads (with early injection). No manipulation in the general architecture of the diesel combustion system. It was kept as it is:

- Direct injection;

- Flat cylinder head.

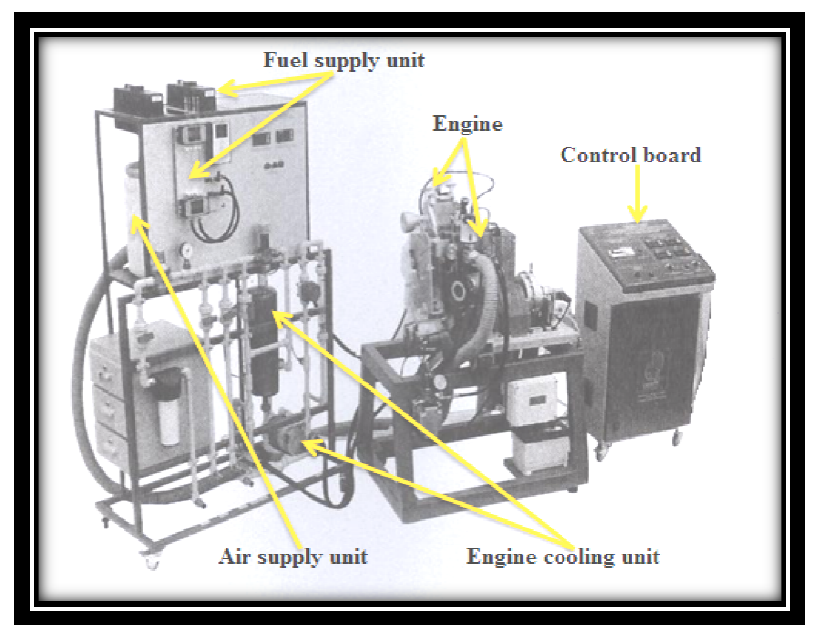

Fig. 1. The engine rig and the measuring instruments

Table 1,

Engine specifications

\begin{tabular}{lc}
\hline Name plate & $\begin{array}{c}\text { varicomp type } \\
\text { (GR06/000/037A) }\end{array}$ \\
\hline The manufacturing year & 1998 \\
Engine type & TD110 \\
Strokes numbers & 4 strokes \\
Piston diameter & $90 \mathrm{~mm}$ \\
Stroke & $85 \mathrm{~mm}$ \\
Swept volume & $541 \mathrm{C} . \mathrm{C}$ \\
Compression ratio & $4-17.5$ \\
Max. power output & $4 \mathrm{~kW}$ at $2800 \mathrm{rpm}$ \\
Max. rpm & 3600 R.P.M \\
Inlet. valve open & $54^{\circ}$ BTDC \\
Inlet valve closed & $22^{\circ}$ ATDC \\
Exhaust valve open & $22^{\circ}$ BTDC \\
Exhaust valve closed & $54^{\circ}$ BTDC \\
\hline
\end{tabular}

Referring to the study of the different HCCI concepts, the use of an early injection strategy was chosen. The dilemma with this method is how to avoid the collision of the fuel with the combustion chamber wall. Therefore, the primary point of this concept is to use a narrow-angle of the spray cone (less than 100 degrees) to reduce fuel collision with the wall of the combustion chamber and to improve the fuel-air mixing, while there is considerable flexibility in the area of the injection. The common rail fuel injection system has been selected because of the continuous increase in its flexibility.

However, the early injection can cause advanced ignition timing and knock. Therefore, it can be a problem. The compression ratio effect was investigated starting from $\mathrm{CR}=12: 1$ to $14.5: 1$ at full load operational cases (full load concept means any more load will cause knock).

The nitrogen oxides (NOx), unburned hydrocarbon $\mathrm{UBHC}, \mathrm{CO}_{2}$, and $\mathrm{CO}$ concentration were measured by Multi-gas mode 4880 emissions analyzer. This device was calibrated at Central Organization for Standardization and Quality Control in Baghdad.

The engine noise (overall sound pressure) measured by a precision sound level meter equipped with microphone type 4615 ; the device was calibrated by standard calibrator meter type pisto-phone 4220.

The equivalence ratio which determined from the measured air and fuel flow rates to the engine, defined as [14]:

$\varnothing=\frac{\text { actual fuel/air ratio }}{\text { stoichiometric fuel/air ratio }}$

The following equations used to calculate the engine performance parameters [14]:

1- Brake power

$b p=\frac{2 \pi * N * T}{60 * 1000} \quad k W$

2- Fuel mass flow rate

$$
\dot{m}_{f}=\frac{v_{f} \times 10^{-6}}{1000} \times \frac{\rho_{f}}{\text { time }} \mathrm{kg} / \mathrm{sec}
$$

3- Volumetric efficiency

$$
\begin{aligned}
& \dot{m}_{\text {a,act. }}=\frac{12 \sqrt{h_{o} * 0.85}}{3600} \times \rho_{\text {air }} \frac{\mathrm{kg}}{\mathrm{sec}} \\
& \dot{m}_{a_{\text {theo. }}}=V_{\text {s.n }} \times \frac{\mathrm{N}}{60 * 2} \times \rho_{\text {air }} \frac{\mathrm{kg}}{\mathrm{sec}} \\
& \eta_{\text {vol. }}=\frac{\dot{m}_{\text {a,act. }}}{\dot{m}_{a_{\text {theo. }} .}}
\end{aligned}
$$

4- Brake specific fuel consumption

$$
b s f c=\frac{\dot{m}_{f}}{b p} \times 3600 \frac{\mathrm{kg}}{\mathrm{kW} \cdot \mathrm{hr}}
$$

5- Total fuel heat

$Q_{t}=\dot{m}_{f} \times L C V \quad k W$

6- The lost power to overcome the friction (friction power):

$f_{p}=\frac{T \times N}{348.067}$

7- Mechanical efficiency:

$\eta_{m}=\frac{b_{p}}{I_{p}}=\frac{b_{p}}{b_{p}+f_{p}}$ 
8- Brake thermal efficiency

$\eta_{b t h .}=\frac{b p}{Q_{t}} \times 100 \quad \%$

\section{Tests Procedure}

After running the engine for a warming period to achieve engine steady state conditions as the oil temperature is at $70{ }^{\circ} \mathrm{C} \pm 5$, and cooling water temperature is at $70{ }^{\circ} \mathrm{C} \pm 5$, the experiments were carried out. The engine design and operating parameters have been varied at the following levels:

1. Type of fuel included pure gasoline fuel (base case as a normal spark ignition engine).

2. The engine load varied from no load to full load.

3. The fuel injection timing ranged from 10 to 45 ${ }^{\circ}$ BTDC in steps of $5^{\circ}$.

4. The engine speed fixed at $1500 \mathrm{rpm}$.

In the first tests set, the engine operated in the spark ignition mode. Tests of engine performance and exhaust emissions were conducted as a basis for comparison. The engine was run at no load condition, and its speed was adjusted to $1500 \mathrm{rpm}$ $\pm 20 \mathrm{rpm}$. The engine operated at a constant speed, and then it was gradually loaded. The experiments conducted at maximum load levels. The engine left running for a period of not less than three minutes for each load condition to confirm the operation stability, and then each test was replicated three times to ensure the tests repeatability.

\section{Results and Discussion}

Fig. 2 indicates that brake power (bp) increases with increasing compression ratio until it reaches it maximum value, which is called the higher useful compression ratio (HUCR). The HUCR for the gasoline engine is 8:1 as the results clarified. Any further increase in compression ratio led to high pressure rates and abnormal combustion (knock) that forced to reduce the engine load highly.

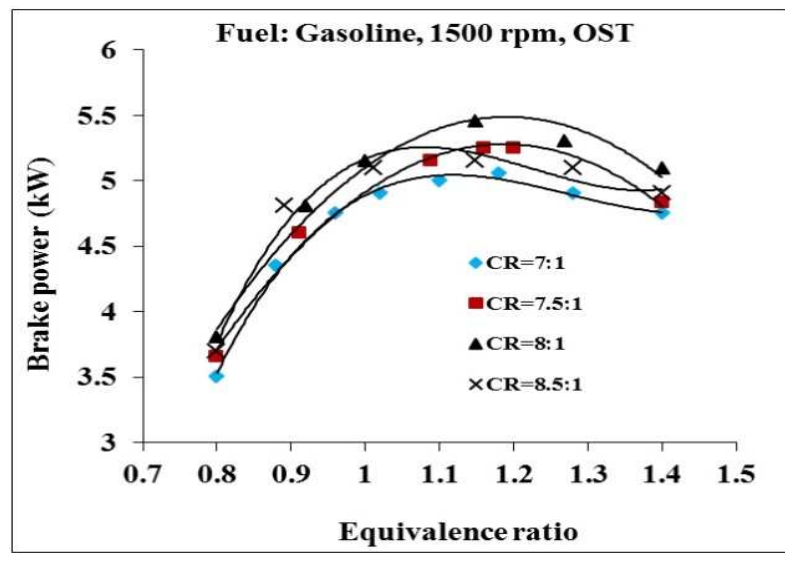

Fig. 2. Compression ratio effect on brake power for wide range of equivalence ratios of gasoline fuel.

The HUCR for HCCI engine was 14:1, as Fig. 3 shows. The resulted HCCI engine higher useful compression ratio confirms what many researches about the suitable compression ratio for HCCI engine. These studies pointed to have a moderate compression ratio to control the better start of combustion [2, 5, 6 \& 12].

Fig 4 compares the resulted bp at HUCR for the two studied modes. HCCI engines operated in very lean mixture lied between $(\varnothing=0.2$ to 0.7$)$ while gasoline started from $\varnothing=0.8$. The reduction in brake power for the HCCI mode was 6\% compared to SI mode. Also, the resulted bp at very lean equivalence ratio for HCCI mode was high, due to higher compression ratio.

The equivalence ratio affects both fuel concentration and oxygen concentration. However, since HCCI engines operate at lean equivalence ratios; the equivalence ratio has a stronger influence on fuel level than on oxygen concentration. The increasing of the equivalence ratio means increasing the fuel concentration, which results in higher reaction rate and higher brake power.

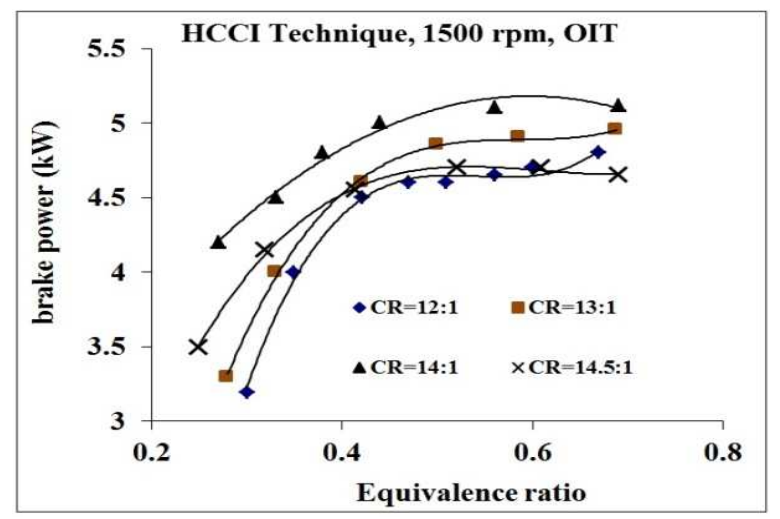

Fig. 3. Compression ratio effect on brake power for wide range of equivalence ratios for $\mathrm{HCCI}$ engine. 


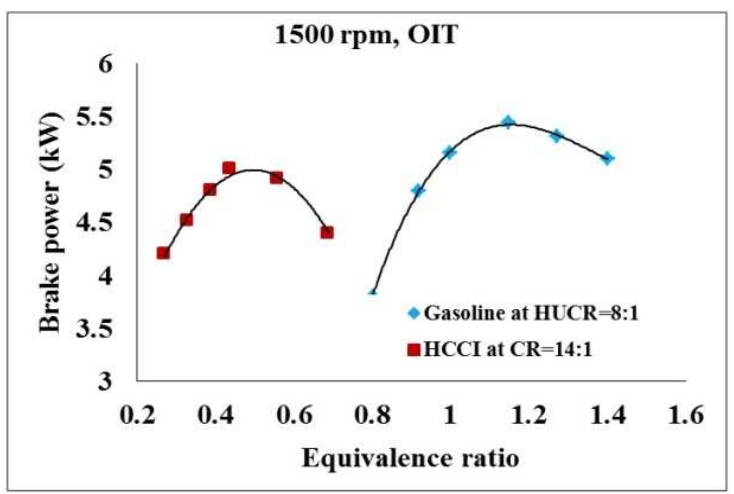

Fig. 4. bp of the two systems at HUCR for each one for wide range of equivalence ratio.

Brake specific fuel consumption (bsfc) for HCCI engine reduced about $28.35 \%$ from gasoline engine's bsfc, as Fig. 5 indicates. The lean operation reduces the fuel consumption while preserves the resulted power high.

For comparison purposes, the relationship between the bp and the bsfc for the two engines was plotted as in the Fig. 6. The brake specific fuel consumption of the HCCI engine was less at equal brake powers of the both engines, which means better combustion and fewer engine losses in HCCI mode.

The lean mixture combustion produces lower exhaust gas temperatures compared to richer mixtures. As Fig. 7 shows HCCI engine produced lower exhaust gas temperature compared with the SI engine.

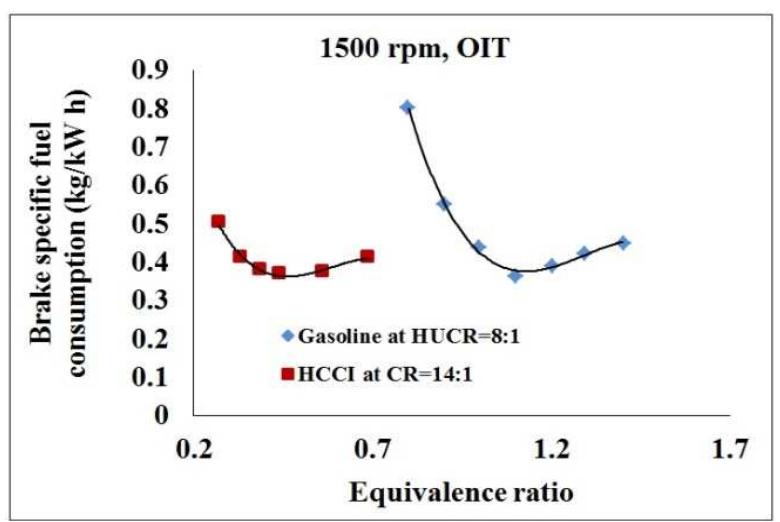

Fig. 5. bsfc of the two systems at HUCR for each one for wide range of equivalence ratio.

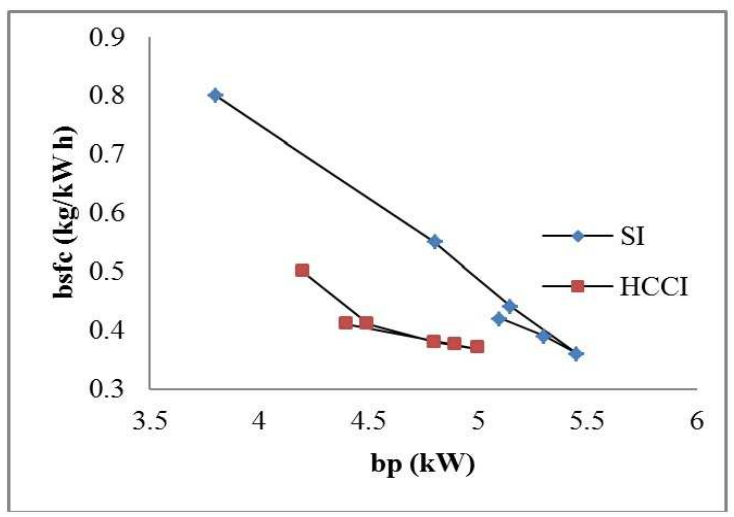

Fig. 6. The bsfc for variable bp of the two systems at HUCR for each one.

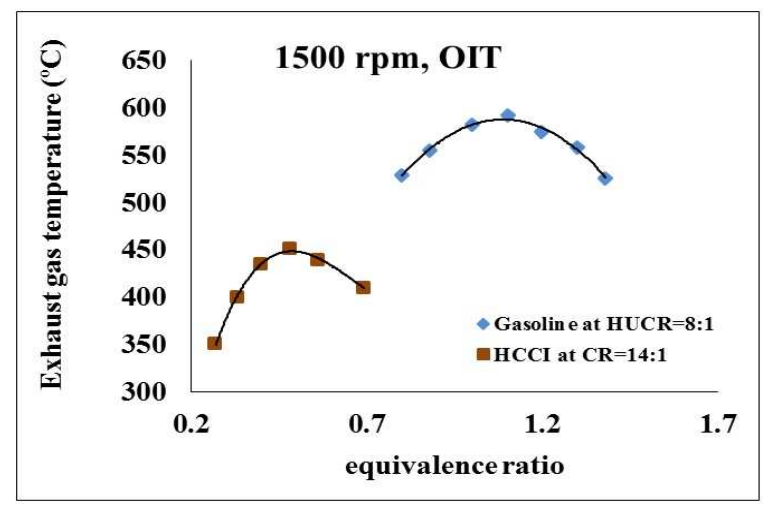

Fig. 7. Exhaust gas temperatures of the two systems at HUCR for each one, for wide range of equivalence ratios.

Operating the engine with very lean mixtures means increasing the air portion in the mixture, result in higher volumetric efficiency. Also, due to lower temperature of the combustion chamber that will reduce its temperature and increases the interring mass flow rate for the subsequent cycle.

As Fig. 8 represents, HCCI has higher volumetric efficiency compared with a gasoline engine.

The mechanical efficiency of HCCI reduced with about $19.86 \%$ in relation to the SI engine, as Fig. 9 represents. Brake power reduction due to working on lean mixtures and fp increased due to $\mathrm{CR}$ resulting in mechanical efficiency reduction. 


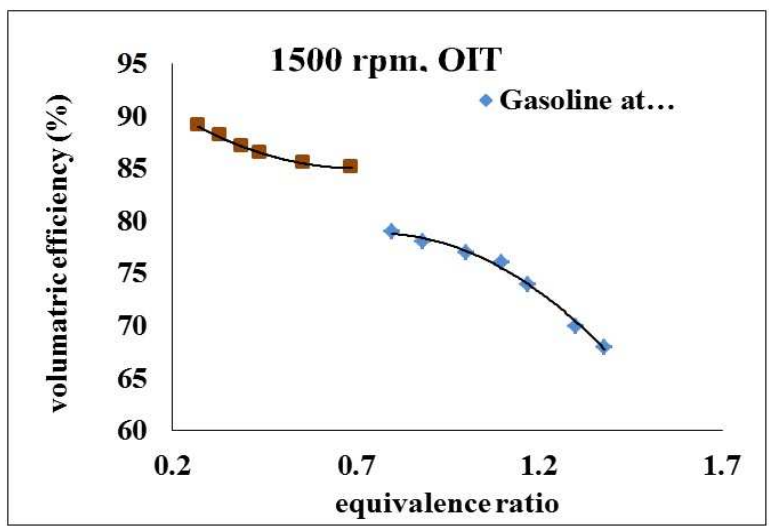

Fig. 8. Volumetric efficiency of the two systems at HUCR for each one, for wide range of equivalence ratio

HCCI engine produced high brake power with lower brake specific fuel consumption compared with the SI engine. As Fig. 10 shows, the brake thermal efficiency of HCCI exceeded gasoline engine.

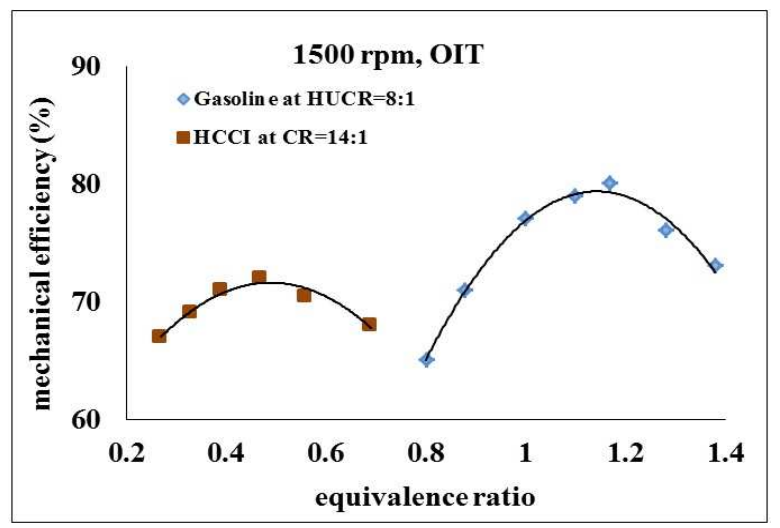

Fig. 9. Mechanical efficiency of the two systems at HUCR for each one, for wide range of equivalence ratios

HCCI engine distinguished by near zero NOx concentrations, as Fig. 11 represents. The engine operation with lean equivalence ratio produced lower temperatures inside the combustion chamber. These temperatures are not enough for $\mathrm{N}_{2}$ and $\mathrm{O}_{2}$ to react effectively.

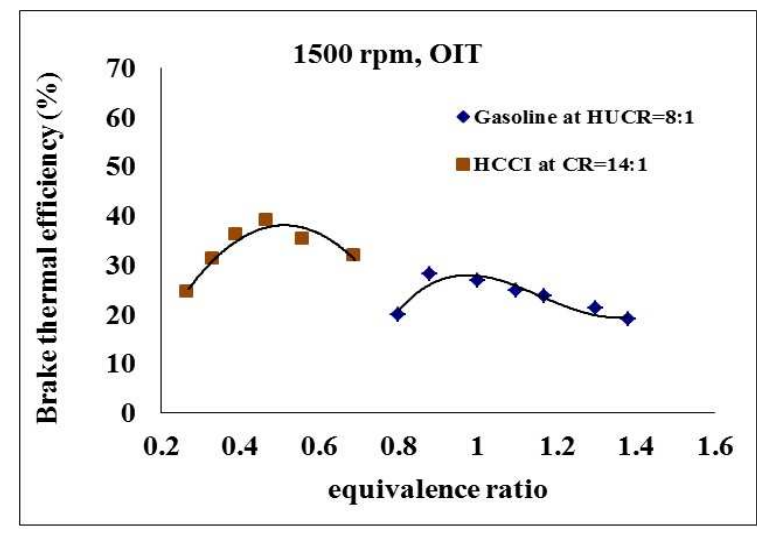

Fig. 10, brake thermal efficiency of the two systems at HUCR for each one, for wide range of equivalence ratio.

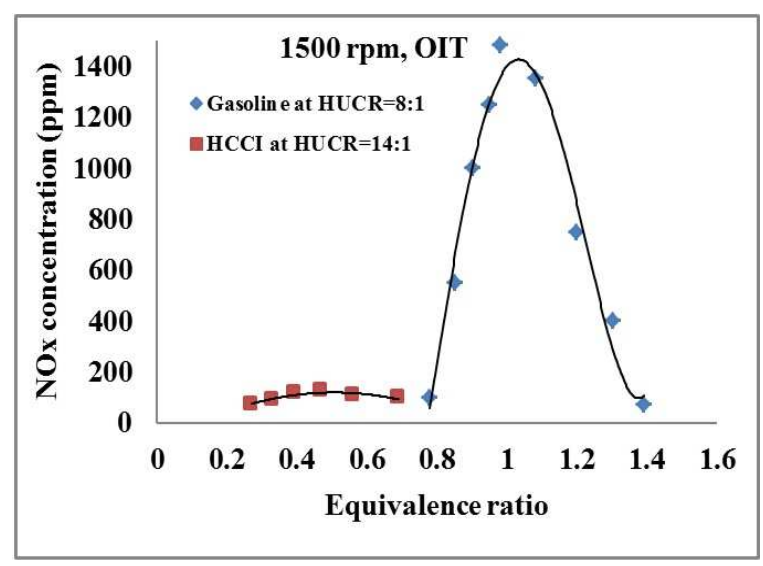

Fig. 11. NOx concentrations of the two systems at HUCR for each one, for wide range of equivalence ratio

Because of air overabundance in lean mixtures operation, the resulted $\mathrm{CO}_{2}$ concentrations were limited to the minimum values, as Fig. 12 appears. The $\mathrm{CO}_{2}$ levels are at the minimal values compared to those produced from the SI engine.

Fig. 13 represents the emitted CO concentrations for the two tested engines. Partial oxidation of fuel to $\mathrm{CO}$ can occur at extremely lean mixtures. Three temperatures govern the HCCI engine. The required auto-ignition temperature to get fuel/air mixture ignited; the combustion temperature must reach at least 1400 $\mathrm{K}$ to have good combustion efficiency, in the same time, this temperature must not increase to more than $1900 \mathrm{~K}$ to prevent the formation NOx. 


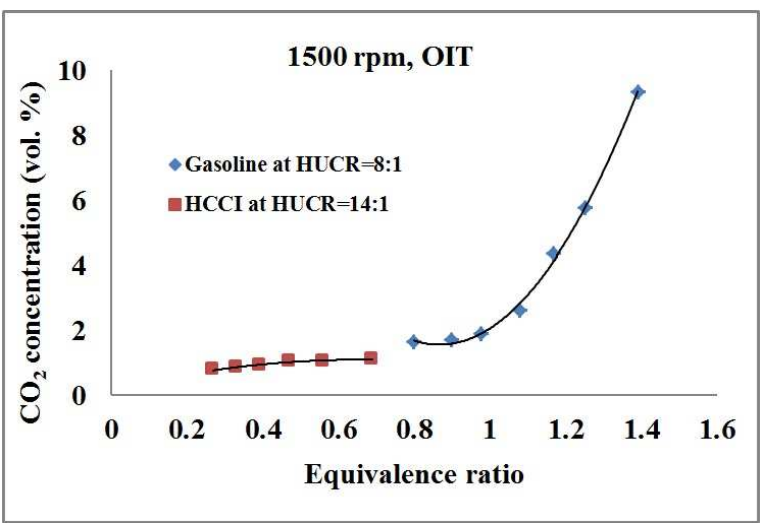

Fig. 12. $\mathrm{CO}_{2}$ concentrations of the two systems at HUCR for each one, for wide range of equivalence ratio.

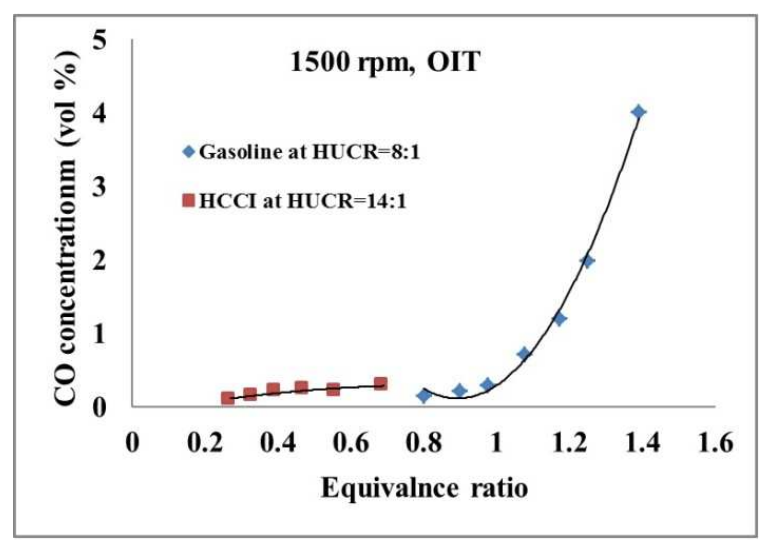

Fig. 13. CO concentrations of the two systems at HUCR for each one, for wide range of equivalence ratio.

The UBHC concentrations in the recent study seem lower than the SI engine levels depending on the optimal gasoline injection timing that provides better air-fuel mixture homogeneity.

Fig. 15 manifests the engine noise, which increased with increasing equivalence ratio, but HCCI produced lower noise with about $26.68 \%$ compared to the gasoline engine. The reactivity of the fuel-air charge is too high at rich mixtures, where the burn rate becomes extremely high at these ratios. The pressure rates inside combustion chamber increase resulting in mechanical stresses and noise.

UNHC concentrations behaved as $\mathrm{CO}$ and $\mathrm{CO}_{2}$ concentrations, and stayed at the minimal values, as Fig. 14 represents. It can be observed that UBHC had higher values at $\varnothing=0.2$, and reduced from its value while moving towards $\varnothing=0.7$, the combustion temperatures increase with increasing fuel quantity in the mixture, and this increment reduces UBHC concentration although it was little.

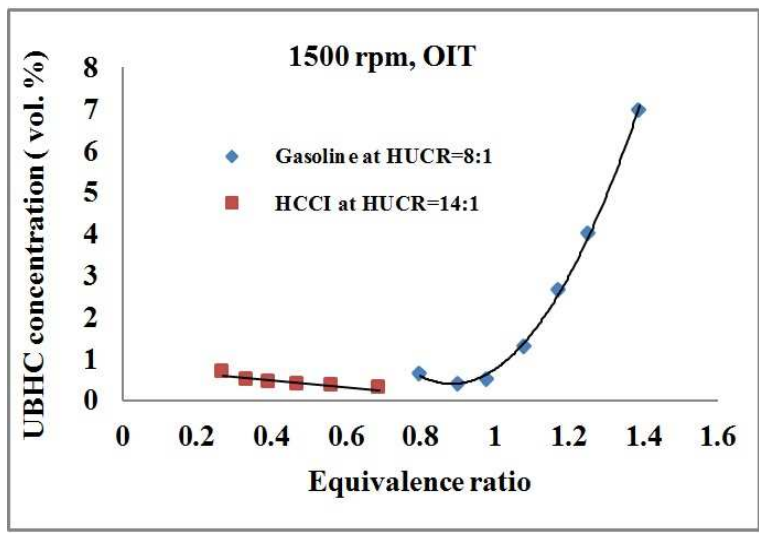

Fig. 14. UBHC concentrations of the two systems at HUCR for each one, for wide range of equivalence ratio.

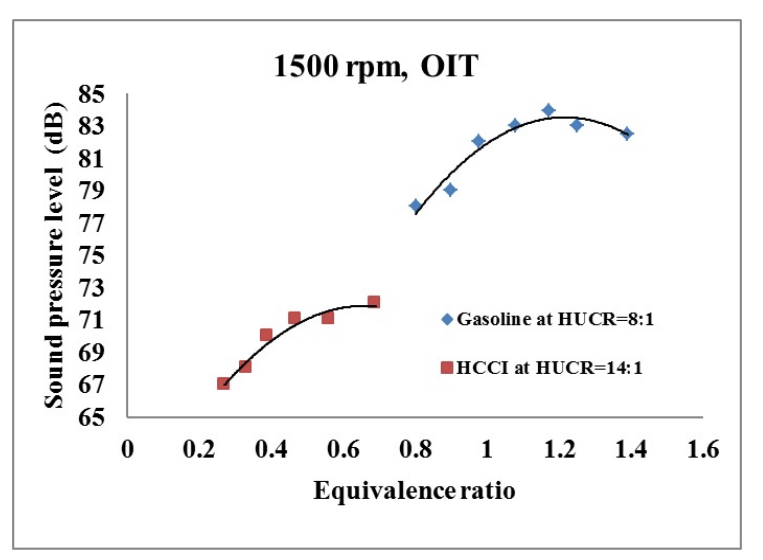

Fig. 15. noise level of the two systems at HUCR for each one, for wide range of equivalence ratio.

\section{Conclusions}

HCCI engine equivalence ratio is usually very lean and strongly diluted; the average peak temperature is much lower than that of the SI mode. The heat losses from HCCI engine are reduced, and the formation of NOx is avoided to a large extent; NOx emissions of HCCI engines are often near zero.

Emissions of $\mathrm{CO}$ and $\mathrm{HC}$ were lower than the SI engine emitted emissions. Fuel consumption values have the potential to be approximately $28 \%$ less than SI mode. Also, HCCI mode produced brake power lower than the SI engine with about $6 \%$. The HCCI engines have higher brake thermal efficiencies compared to SI engines.

\section{Notation}

BTDC before top dead centre

bp brake power

BTE brake thermal efficiency 


$\begin{array}{ll}\mathrm{CO}_{2} & \text { carbon dioxide } \\ \mathrm{CO} & \text { carbon monoxide } \\ \mathrm{CR} & \text { compression ratio } \\ \mathrm{CA} & \text { crank angle } \\ \mathrm{dB} & \text { decibel } \\ \mathrm{DI} & \text { direct injection } \\ \mathrm{fp} & \text { friction power } \\ \mathrm{IT} & \text { injection timing } \\ \mathrm{N} & \text { engine speed (rpm) } \\ \text { NOx } & \text { nitrogen oxides } \\ \text { LCV } & \text { Lower calorific value } \\ \text { OIT } & \text { Optimum injection timing } \\ \text { OST } & \text { Optimum spark timing } \\ \text { T } & \text { engine torque } \\ \text { UBHC } & \text { unburnt hydrocarbon } \\ \text { Vsn } & \text { swept volume }\end{array}$

Greek letter

$\varnothing$

Equivalence Ratio

\section{Acknowledgements}

The author would like to thank the Technical Collage, the Middle Technical University for their support to achieve this research.

\section{References}

[1] Martins $M$, Zhao $H$, Performance and Emissions of a 4-cylinder gasoline engine with controlled auto-ignition, J. of the Braz. Soc. of Mech. Sci. \& Eng, vol. 36, No. 4, pp. 436-440, 2012.

[2] Wu Z, Bao T, Zhang Q, Yan S and Deng J, Experimental study on spray combustion characteristics of gasoline-diesel blended fuel in a controllable active thermo-atmosphere, Fuel, vol. 135, pp. 374-379, 2014.

[3] Coskun G, Soyhan H S, Demir U, Turkcan A, Ozsezen A N and Canakci M, Influences of second injection variations on combustion and emissions of an HCCI-DI engine: experiments and CFD modeling, Fuel, vol. 136, pp. 287-294, 2014.

[4] Ghazikhani M, Kalateh M R, Toroghi Y K, and Dehnavi M, An experimental study on the effect of premixed and equivalence ratios on $\mathrm{CO}$ and $\mathrm{HC}$ emissions of dual fuel HCCI engine, Proceedings of World Academy of Science, Engineering and Technology, vol. 40, 2009.
[5] Turkcan A, Ozsezen A N, and Canakci M, Experimental investigation of the effects of different injection parameters on a direct injection HCCI engine fueled with alcoholgasoline fuel blends, Fuel Processing Technology, vol. 126, pp. 487-496, 2014.

[6] Su H, Vikhansky A, Mosbach S, Kraft M, Bhave A, Kim K, Kobayashi T and Mauss F, A computational study of an HCCI engine with direct injection during gas exchange, Combustion and Flame, vol. 147, 2006.

[7] Elkelawy M, Yu-Sheng Z, Alm El-Din H, and $\mathrm{Yu} \mathrm{J} \mathrm{Z}$, Challenging and Future of homogeneous charge compression ignition engines; an Advanced and novel concepts review, Journal of Power and Energy Systems, vol. 2, pp. 1108-1119, 2008.

[8] Zhao F, Asmus T W, Assanis D N, Dec J E, Eng $\mathrm{J} A$ and Najt P M, Homogeneous Charge Compression Ignition (HCCI) Engines: Key Research and Development Issues, 1st edition, SAE Inc., Canada, pp. 1-658, 2003.

[9] Patil S G L, Prasad B, Maheswar D, Strategies of combustion control for HCCI engine, International Journal of Emerging Technology and Advanced Engineering, vol. 3, No. 3, pp. 101-107, 2013.

[10] Yao M, Zheng Z, and Liu H, Progress and recent trends in homogeneous charge compression ignition (HCCI) engines, Progress in Energy and Combustion Science, vol. 35, pp. 398-437, 2009.

[11] Ren Z and Zhu G G, Modeling and control of an electric variable valve timing system for SI and HCCI combustion mode transition, 2011 American Control Conference on O'Farrell Street, San Francisco, CA, USA, 2011.

[12] Kung E H, Priyadarshi S, Nese B C and Haworth D C, A CFD investigation of emissions formation in HCCI engines, including detailed NOx chemistry, 2006 Multidimensional Engine Modeling Users' Group Meeting, Detroit, 2006.

[13] Walton S M, He X, Zigler B T, Wooldridge M S, and Atreya A, An experimental investigation of iso-octane ignition phenomena, Combustion and Flame Journal, 2006.

[14] Keating E L, Applied combustion, 2nd edition, Taylor \& Francis Group, LLC, 2007. 


\title{
دراسة مقارنة لمواصفات أداء وملوثات محرك اشتعال بالثرارة ومحرك إشتعال بالانضغاط
}

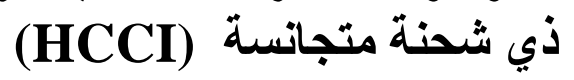

\author{
ناهض محمود علي

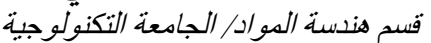

nahidh.mahmood60@gmail.com البريد الالكترونيم

\section{الخلاصة}

يرى العديد من الباحثين أن عملية الاشعال الانضغاطي لشحنة متجانسة بديلا واعدا لمحركات الأشتعال بالشرارة وبالأنضغاط. إذ تعمل محركات

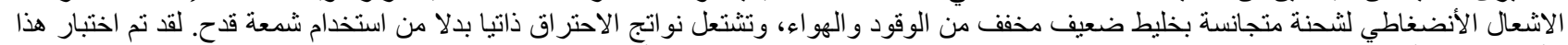

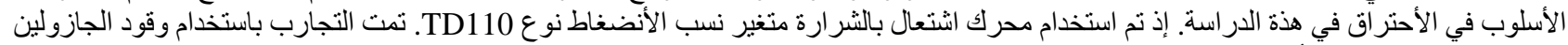

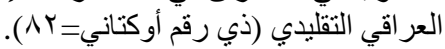

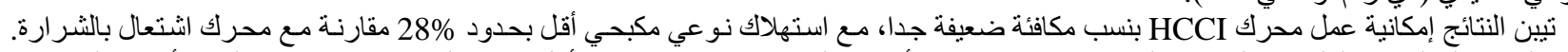

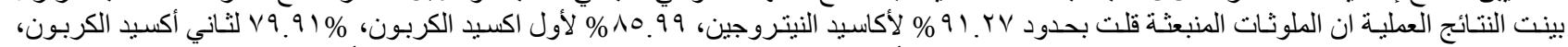

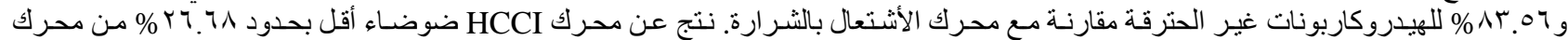
الأشتعال بالثرارة. 